\title{
New invariants and dimensionless numbers: futile renaissance of old fallacies?
}

\author{
ROBERTO F. NESPOLO
}

Instituto de Ecología y Evolución, Universidad Austral de Chile

\begin{abstract}
The necessity of the mathematical description of living processes and the recent advances in theoretical syntheses that fit surprisingly well with real data have led many scientists to experiment with new "generalizations," beginning with allometric equations. I present here, briefly, why caution is needed when allometric equations are multiplied or divided to make new ones. This practice is flawed by old and recognized problems, such as the fallacy of averages combined with misunderstandings that include error propagation, misuse of statistics and confounding scale.
\end{abstract}

Key terms: Fallacy of averages, dimensional analysis, invariants, allometric equations, error term.

\section{INTRODUCTION}

One of the most important aims of science is the quest for generalizations. This has led to an intense competition to find the general principle behind all living systems. One of these is the search for a unifying principle or the invariant that determines physiological attributes in animals (West et al., 1997; Darveau et al., 2002). Physiologists, who have been working experimentally in the subject since a century ago, have identified repeatedly body mass as the main determinant of most physiological variables measured at an organism basis (with conspicuous exceptions such as haematological parameter; see Dunaway and Lewis, 1965). This provided the scaling concept: most physiological, life history and ecological attributes of animals can be expressed as an exponential function of body mass, obtained empirically (Kleiber, 1932; Peters, 1983; Calder, 1984; Schmidt-Nielsen, 1995; $\mathrm{McNab}$, 2001). However, the theoretical development intended to explain the exponent of allometric equations of metabolism yielded multiple underlying causes and considerable debate, which highlights the sharply contrasting approaches developed by different researchers such as experimental physiologists (Darveau et al., 2002; Weibel, 2002) who see a not-so-general causes for energy metabolism and macro ecologists (Brown et al., 1993; West et al., 1997; Marquet, 2000) who defend body size as a single universal determinant to most aspects of animal life. This interesting debate has led to several syntheses regarding the "correct" or the most general exponent for allometric equations for metabolism (Dodds et al., 2001; White and Seymour, 2003).

\section{ALLOMETRIC EQUATIONS MADE SIMPLE?}

Regardless of the biological reality of allometric equations, their usefulness for controlling effects in statistical analyses as a predictable tool in biomedicine or comparative physiology is beyond criticism. However, allometric equations are statistical results of observed data in the form of expectations of model parameters. Given the usefulness of allometric 
equations, it would be very tempting to develop new ones from those that have been empirically reported. This is what Günther et al. (2003) did by multiplying known allometric equations, (maintaining the base and summing exponents) and interpreting the similarities among the resulted exponents as evidence of design parameters, invariant and dimensionless numbers which remain constant even at different periods of life. I will show why this assertion is incorrect due to several methodological reasons related to the use and properties of expectations.

Experimental biologists usually measure several physiological variables in the same individual. The statistical analyses for such results are usually related to mean comparisons. A known relationship in mammalian physiology is the one between maximum metabolic rate (MMR), basal metabolic rate (BMR), non-shivering thermogenesis (NST), and shivering thermogenesis (ST) (see Wunder and Gettinger, 1996; Nespolo et al., 2003a, b)

$$
\mathrm{MMR}=\mathrm{BMR}+\mathrm{NST}+\mathrm{ST}
$$

Although maximum metabolic rate, basal metabolic rates and nonshivering thermogenesis are easy to measure, shivering thermogenesis is more complicated (Nespolo et al., 2003a). Therefore, a reasonable practice would be to compute averages of the former three variables and to calculate ST. Such a procedure would be correct if and only if $\operatorname{Cov}(\mathrm{BMR}, \mathrm{MMR})=\operatorname{Cov}(\mathrm{NST}, \mathrm{MMR})=$ $\operatorname{Cov}(\mathrm{ST}, \mathrm{MMR})=0$. In other words, this is equivalent to assuming that there is no correlation between any of the measured variables and MMR. If, by any chance, this is not the case, the calculation of ST is incorrect. A physiologist would imagine many reasons to find such a correlation, for example, metabolic rate during resting, postabsorptive state (i.e. BMR) includes abdominal and muscle metabolism, which are suppressed during the stressful (cold) conditions needed to elicit thermoregulatory MMR (Nespolo et al., 1999).

More generally, the assumption that $\mu(X Y)=\mu(X) \mu(Y)$, or in terms of expectations, $\mathrm{E}(\mathrm{XY})=\mathrm{E}(\mathrm{X}) \mathrm{E}(\mathrm{Y})$, is true only if $\operatorname{Cov}(X, Y)=0$. This is a special case of what is known as "the fallacy of averages' (Welsh et al., 1988), the most widespread statistical error in biology. To multiply or to divide allometric equations is an analogous problem because the estimates of the regression parameters are weighed averages (i.e., expectations). Günther et al. (2003) fell into this problem when computing 'invariant' numbers. For example, the first of these numbers (IN1) is obtained computing the exponent (b) from the ratio of several allometric equations,

$\mathrm{W}^{\mathrm{b}}=\left(\mathrm{W}^{0.023}\left(\mathrm{~W}^{0.07}\right)^{3}\left(\mathrm{~W}^{0.27}\right)^{3 /} /\left(\mathrm{W}^{0.73} \mathrm{~W}^{-0.68} \mathrm{Q}^{0.99}\right)\right.$

Where $\mathrm{P}=$ systemic arterial pressure, $\mathrm{V}$ $=$ mean blood velocity, $\mathrm{T}=$ duration of one cardiac cycle, $\mathrm{B}=$ basal metabolic rate, $\mathrm{T}_{\mathrm{P}}$ = total peripheral resistance, $\mathrm{Q}=$ total blood volume.

Furthermore, these authors compute IN1 from these variables obtained experimentally in a $(\mathrm{N}=1)$ dog experiencing a number of conditions (standing, and three levels of exercise). Obviously, these variables experience an enormous change in such conditions, ranging from 1.4 to 3.6. However, the ratio of IN1 across conditions is, according to Günther et al. (2003), remarkably constant $(=1.03)$.

There are at least five reasons to find this slight variation of the invariant number purely due to methodological and scaling artefacts. First, what is considered a large o small change? The authors decide that 3.6 times is a 'large' change (basal metabolic rate) and that 1.03 is a 'slight' difference in the computed invariant number. Therefore the 1.4 -fold change reported in systemic arterial pressure should be considered small, large, or perhaps, medium? Avoiding these arbitrary results is the reason why statistics and dispersion measurements exist.

Second, because of scaling effects alone, a logarithmic scale will always show less variation than an arithmetic scale. This is analogous to comparing exponents of allometric equations: the 0.03 difference in an exponent would mean a $100 \%$ change between exercise conditions. Third, the authors use the Barger et al. (1956) dataset obtained for $\mathrm{a} \operatorname{dog}\left(\mathrm{N}=1, \mathrm{~W}_{\mathrm{b}}=21.5 \mathrm{~g}\right)$, 
exposed it to different conditions of exercise, and replaced those values in the allometric equations, which were obtained from a number of different species of mammals with variation in size of several orders of magnitude, as the Peters (1983) compilation shows. Recall that when the variation in size is below one order of magnitude (for example, in intraspecific studies, see Nespolo et al., 2003a, b), the fit of an exponential function to data $\left(\mathrm{Y}=\mathrm{AW}_{\mathrm{b}} \mathrm{B}\right)$ is not necessarily better and is usually worse than a linear function $\left(\mathrm{Y}=\mathrm{A}+\mathrm{BW}_{\mathrm{b}}\right)$.

Fourth, when a variable with an error is multiplied or divided, the error term is always geometrically magnified. Thus the invariant number computed from the ratio and multiplication of six different allometric equations, each containing a residual term, should contain a huge error term. Fifth, there is still the fallacy of averages confounding these results: covariance among these variables are not only likely to be non-zero, they (i.e. covariances) are an inherent component of the physiological systems as a whole. For example, it is a known fact that at intense exercise $\mathrm{VO}_{2}$, the oxygen consumption could increase several times, whereas $\mathrm{T}$, the duration of one cardiac cycle is reduced. Hence, both variables present a negative covariance.

Reductionism occurs when a simplistic approach is applied to a complex problem. Equations are formalizations that sometimes describe life with elegant precision. To build new ones from preexisting empirical equations reported in old compilations such as Peters (1983) or Calder (1984) (which, in turn, are reports of older original works) b y ordinary algebraic methods is not a simple or 'holistic' approach. It is just simplistic, and therefore, erroneous.

\section{AKNOWLEDGEMENTS}

The author aknowledges DID (Dirección de Investigación y Desarrollo) grant No. S200441

\section{REFERENCES}

BARGER AC, RICHARDS V, METCALFE J, GUNTHER B (1956) Regulation of the circulation during exercise cardiac output (direct Fick) and metabolic adjustments in the normal dog. Am J Physiol 184: 613-623

BROWN JH, MARQUET PA, TAPER ML (1993) Evolution of body size: consequences of an energetic definition of fitness. Am Naturalist 142: 573-584

CALDER WA (1984) Size, function and life histories. $1^{\text {st }}$ ed. New York: Harvard

DARVEAU CA, SUÁREZ RK, ANDREWS RD, HOCHACHKA PW (2002) Allometric cascade as a unifying principle of body mass effects on metabolism. Nature 417: 166-170

DODDS PS, ROTHMAN DH, WEITZ JS (2001) Reexamination of the "3/4-law" of metabolism. J Theoretical Biol 209: 9-27

DUNAWAY PB, LEWIS LL (1965) Taxonomic relation of erythrocyte count, mean corpuscular volume, and body-weight in mammals. Nature 205: 481-484

GÜNTHER B，MORGADO E, JIMÉNEZ R (2003) Homeostasis and heterostasis: from invariant to dimensionless numbers. Biol Res 36: 211-221

KLEIBER M (1932) Body size and metabolism. Hilgardia 6: $315-352$

MARQUET PA (2000) Invariants, scaling laws, and ecological complexity. Sci 289: 1487-1488

MCNAB BK (2002) The physiological ecology of vertebrates. A view from energetics, $1^{\text {st }}$ ed. Cornell: Comstock

NESPOLO RF, OPAZO JC, ROSENMANN M, BOZINOVIC F (1999) Thermal acclimation, maximum metabolic rate and nonshivering thermogenesis in Phyllotis xanthopygus (Rodentia) inhabiting the Andean range. J Mammal 80: 742-748

NESPOLO RF, ARIM M, BOZINOVIC F (2003a) Body size as a latent variable in a structural equation model: thermal acclimation and energetics of the leaf-eared mouse. J Exp Biol 206: 2145-2157

NESPOLO RF, BACIGALUPE LD, BOZINOVIC F (2003b) Heritability of energetics in a wild mammal, the leaf-eared mouse (Phyllotis darwini). Evolution 57: $1679-1688$

PETERS RH (1983) The ecological implications of body size, $1^{\text {st }}$ ed. Cambridge: Cambridge University Press

SCHMIDT-NIELSEN K (1995) Animal physiology: adaptation and environment, $4^{\text {th }}$ ed. Cambridge: Cambridge University Press

WEIBEL ER (2002) The pitfalls of power laws. Nature 417: $131-132$

WELSH AH, PETERSON AT, ALTMANN SA (1988) The fallacy of averages. The Am Naturalist 132: 277-288

WEST GB, BROWN JH, ENQUIST BJ (1997) A general model for the origin of allometric scaling laws in biology. Sci 276: 122-126

WHITE CR, SEYMOUR RS (2003) Mammalian basal metabolic rate is proportional to body $\operatorname{mass}^{2 / 3}$. Proc Natl Acad Sci USA 100: 4046-4049

WUNDER BA, GETTINGER RD (1996) Effects of body mass and temperature acclimation on the nonshivering thermogenic response of small mammals. In: GEISER F, HULBERT AJ, NICOL SC (eds) Adaptations to the Cold: Tenth International Hibernation Symposium. Armidale: University of New England Press. pp: 131139 